\title{
A VUELTAS CON LA REGULACIÓN DE LA RESPONSABILIDAD DEL ESTADO LEGISLADOR (Un nuevo intento introducido en el Proyecto de Ley de Régimen jurídico del sector público de limitar el alcance de la responsabilidad del Estado Legislador, esta vez en su vertiente del ilícito legislativo) ${ }^{1}$
}

\author{
Roberto Galán Vioque \\ Profesor Titular de Derecho Administrativo \\ Universidad de Sevilla \\ rgvioque@us.es
}

\section{INTRODUCCIÓN}

En la exposición de motivos del Proyecto de Ley de Régimen jurídico del Sector público² se recoge como una de sus principales novedades la regulación de la responsabilidad por los daños causados por leyes inconstitucionales o contrarias al Derecho de la Unión Europea, la denominada responsabilidad por ilícito legislativo. No es esta la primera vez que se legisla sobre la llamada responsabilidad del Estado Legislador. Aunque sí es la primera ocasión en la que en un texto normativo se hace referencia expresa, con este tenor literal de responsabilidad del Estado Legislador ${ }^{3}$, a esta modalidad de responsabilidad de los poderes públicos, cuya garantía se consagra en el artículo 9.3 de nuestra Constitución, con lo que parece que se puede dar por zanjada la polémica doctrinal que se ha planteado en nuestra doctrina sobre su existencia ${ }^{4}$.

En la Ley 30/1992, de 26 de noviembre, de Régimen jurídico de las Administración Públicas y del procedimiento administrativo común (en lo sucesivo LRJPAC) se introdujo ya inicialmente en su artículo 139.3 una pretendida regulación de la responsabilidad por los daños causados por leyes válidas que en realidad perseguía dejar sin efecto esta clase de responsabilidad. Parece que esta novedosa regulación que ahora se quiere aprobar tiene esta misma intencionalidad.

\section{EL MANTENIMIENTO DE LA DISCUTIBLE REGULACIÓN DE LA RESPONSABILIDAD POR LA APLICACIÓN DE ACTOS LEGISLATIVOS VÁLIDOS INTRODUCIDA EN LA LEY 30/1992, DE 26 DE NOVIEMBRE, DE RÉGIMEN JURÍDICO DE LAS ADMINISTRACIONES PÚBLICAS Y DEL PROCEDIMIENTO ADMINISTRATIVO COMÚN}

El Proyecto de Ley de Régimen jurídico del Sector público mantiene con muy ligeros retoques el contenido del artículo 139.3 de la LRJPAC que ahora se traslada a su artículo 32.2 disponiendo que <<[a] símismo, los particulares tendrán derecho a ser indemnizados por las Administraciones Públicas de toda lesión que sufran en sus bienes y derechos como consecuencia de la aplicación de actos legislativos de naturaleza no expropiatoria de derechos que no tengan el deber jurídico de soportar cuando así se establezca en los propios actos legislativos y en los términos que en ellos se especifiquen>>.

Aunque de su tenor literal se pueda desprender que en nuestro ordenamiento jurídico la indemnización de los daños causados por leyes no expropiatorias se encuentra en manos del propio Legislador que causa el daño, lo cierto es que la jurisprudencia tanto del Tribunal Constitucional como del Tribunal Supremo ha acabado arrum-

1 Quiero agradecer a los Profesores S. MUÑOZ MACHADO y M. REBOLLO PUIG y al Letrado del Consejo de Estado M. BARRIO ANDRÉS la invitación que se me ha hecho para participar en este número monográfico de Documentación administrativa dedicado a los Proyectos de las Leyes de Procedimiento administrativo común de las Administraciones Públicas y de Régimen jurídico del Sector público.

2 Publicado en el Boletín oficial de las Cortes Generales, $\mathrm{n}^{\circ}$ 154-1, Serie A, págs. 1 a 88, que se puede consultar en http://www.congreso.es/public oficiales/L10/CONG/BOCG/A/BOCG-10-A-154-1.PDF.

3 En el primer inciso del segundo párrafo de su artículo 32.2.

4 Me refiero a la polémica que se suscitó entre GARCIA DE ENTERRÍA, E., recogida entre otras en su La responsabilidad patrimonial del Estado Legislador en el Derecho español, Thomson-Civitas, Cizur Menor, 2007, $2^{\text {a }}$ edición, págs. 102 y ss. y la tesis que defendí en La Responsabilidad del Estado Legislador, CEDECS, Barcelona, 2001, también recogida en De la teoría a la realidad de la responsabilidad del Estado Legislador, Revista de Administración Pública, $n^{\circ}$ 155, 2001, págs. 301 y ss. Polémica que queda reflejada en la recensión que BORRAJO INIESTA, I. hizo a la primera edición del citado libro de GARCÍA DE ENTERRÍA publicada en Revista de Administración Pública, nº 168, 2005 , pág. 516. 
bando esta interpretación 5 . La finalidad clara de este precepto era la de intentar poner fin a una doctrina sobre la responsabilidad del Estado Legislador que se había venido gestando por ambos Tribunales en torno a la avalancha de reclamaciones de responsabilidad presentadas por los daños causados por el adelanto legal de la edad de jubilación de los empleados públicos en la década de los años ochenta ya del siglo pasado ${ }^{6}$. Aunque inicialmente pudo parecer que consiguió su objetivo porque en la primera sentencia del Pleno de las Sala Tercera del Tribunal Supremo, la de 30 de noviembre de $1.992^{7}$, que resolvió este asunto desestimándolo, se invocó obiter dicta este precepto que se había publicado tan sólo tres días antes, poco más tarde se acabaría reconociendo responsabilidad por los daños causados por leyes válidas en la histórica STS de 5 de marzo de $1993^{8}$ que indemnizó a una empresa pesquera por los daños que le había causado la supresión sorpresiva, por parte de la Ley orgánica 10/1985, de 2 de agosto, por la que se autorizó la celebración del Tratado de Adhesión de España a la Comunidad Económica Europea, de unos beneficios fiscales.

La responsabilidad patrimonial derivada de leyes válidas acabaría recibiendo su "espaldarazo" definitivo con la STC 28/1.997, de 13 de febrero en la que el alto Tribunal tras rechazar que la ley cuestionada, una ley balear que imponía una "moratoria urbanística", tuviera un carácter expropiatorio afirmó con rotundidad que respecto a la posibilidad de que se pudieran indemnizar los daños producido por esta ley que guardaba silencio sobre esta cuestión <<.ha de entenderse que ese extremo quedará sometido a la normativa general del ordenamiento jurídico sobre la responsabilidad patrimonial por actos de los poderes públicos que procede otorgar a quienes, por causa de interés general, resulten perjudicados en sus bienes y derechos >> (F.J. $\left.7^{\circ}\right)^{9}$. Con lo quedaba desvirtuada la finalidad perseguida con el artículo 139.3 de la LRJPAC.

\section{LA NUEVA REGULACIÓN DE LA RESPONSABILIDAD POR LEYES INCONSTITUCIONALES O CONTRARIAS AL DERECHO DE LA UNIÓN EUROPEA CONTENIDA EN EL PROYECTO DE LEY DE RÉGIMEN JURÍDICO DEL SECTOR PÚBLICO}

Habría que esperar hasta principios del siglo XXI para que aparecieran los primeros fallos en los que se empezarán a reconocer también indemnizaciones por ilícitos legislativos. Resulta curioso pero al mismo tiempo que se elaboraba la LRJPAC se estaba alumbrando en el ámbito de la Unión Europea una acción de responsabilidad contra los Estados miembros por sus infracciones al Derecho de la Unión Europea que también iba a alcanzar a la reparación de los perjuicios sufridos por los particulares como consecuencia de los incumplimientos que fueran imputables a los poderes legislativos nacionales. Así en la paradigmática sentencia del entonces Tribunal de Justicia de la Comunidad Europea, de 19 de noviembre de 1.991, dictada en el caso Francovich y Bonifaci ${ }^{10}$ se proclamó que esta responsabilidad de los Estados resultaba algo <<inherente al sistema del Tratado >>1". Esta afirmación se hizo precisamente en relación con unos perjuicios sufridos como consecuencia de una omisión del Legislador italiano que dejó sin trasponer una Directiva europea de carácter laboral. Más tarde el Tribunal de Luxemburgo afianzaría de forma definitiva esta revolucionaria jurisprudencia en su decisiva sentencia, de 5 de marzo de 1996, Brasserie du pechêur SA y República Federal de Alemania y The Queen y Secretary of State for Transport ex parte: Factortame

5 Sobre la interpretación de este anodino precepto puede verse a ALONSO GARCíA, C.M., La responsabilidad patrimonial del EstadoLegislador, Madrid, Marcial Pons, 1.999, pág. 86 y ss.; CELDRÁN RUANO, J., La responsabilidad del Estado por actos de aplicación de leyes: aproximación histórica y significado actual, Servicio de publicaciones de la Universidad de Murcia, Murcia, 1.996, pág. 65; GARCíA-ALVÁREZ, G. en BERMEJO

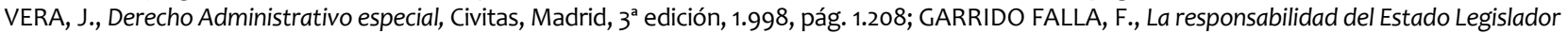
en la nueva Ley 30/1.992 y en la Sentencia del Tribunal Supremo de 30 de noviembre de 1.992, Revista Española de Derecho Administrativo, $\mathrm{n}^{\circ} 77,1993$, págs. 127 y 128; GONZÁLEZ-VARES IBÁÑEZ, S., Responsabilidad del Estado Legislador: Pautas de la jurisprudencia para determinar la aplicación del artículo 139.3 de la Ley 30/1.992, Revista Española de Derecho Administrativo, n 104, 1.999, pág. 641; MARTíN REBOLLO, L., Responsabilidad Patrimonial por actos legislativos: una discutible elaboración jurisprudencial en expansión, Actualidad Jurídica Aranzadi, n 556, 2002, pág. 1 y La responsabilidad patrimonial de las Administraciones Públicas en España La Responsabilidad de las Administraciones Públicas en España La responsabilidad patrimonial de las Administraciones Públicas en España en BARNES VÁZQUEZ, J. (coord.), Propiedad, expropiación y responsabilidad: la garantía indemnizatoria en el derecho europeo y comparado : Unión Europea, Convenio europeo de derechos humanos, España, Alemania, Francia, Italia, Civitas, 1996, pág. 852 y QUINTANA LÓPEZ, T., La responsabilidad del Estado Legislador, Revista de Administración Pública, nº 135, 1994, págs. 126 y ss.

6 MONTORO CHINER, M.J. diría gráficamente que este precepto <<parece que retrate la situación sufrida, tan criticada, de la jubilación anticipada de los funcionarios al rebajarse la edad de jubilación en la Ley 30/1.984 en La responsabilidad patrimonial de las Administraciones Públicas en la Ley 30/1.992 de Régimen jurídico de las Administraciones Públicas y del Procedimiento administrativo común, Revista catalana de Derecho Público, $n^{\circ} 16$, 1.993, pág. 54. Igualmente LEGUINA VILLA considera que es una reacción del Parlamento frente a la jurisprudencia del Tribunal Supremo y de algunos Tribunales Superiores de Justicia favorables al reconocimiento de responsabilidad legislativa, cuyos fallos serían <<la razón última de este precepto〉> en La nueva Ley de régimen jurídico de las Administraciones Pública y del procedimiento administrativo común, Tecnos, Madrid, 1.993 , pág. 412.

$7 \quad$ RJ 1992/8769.

8 RJ 1993/1623, después reiterada en las posteriores SSTS de 27 de junio de 1.994 STS de 16 de septiembre de 1.997 (RRJJ 1994/4.981 y 6.411).

9 En su posterior STC 112/2006, de 5 de abril de 2006 (F.J. $21^{\circ}$ con un interesante voto particular de la entonces Presidenta del Tribunal Constitucional) volvería a pronunciarse tangencialmente sobre la responsabilidad del Estado Legislador.

10 TJCE $1991 / 296$.

11 Parágrafo $35^{\circ}$. 
LTD e.a., ${ }^{12}$-conocida como Brasserie du pechêur/Factortame III- trasladando al ámbito de la responsabilidad de los Estados como mínimo el mismo régimen de responsabilidad que se le aplica a las Instituciones europeas cuando son ellas las que lo infringen, erigiendo al requisito de que se dé una violación suficientemente caracterizada en el eje de esta clase de responsabilidad ${ }^{13}$.

De acuerdo con esta doctrina el Tribunal Supremo, en el conocido como asunto Canal Satélite Digital, dictó una paradigmática sentencia de 12 junio de $2003^{14}$ en la que se indemnizó a esta entidad mercantil por los daños que le había causado el Real Decreto-ley 1/1997 de 31 de enero, por el que se incorpora al Derecho español la Directiva 95/47 CE, de 24 de octubre de 1995, del Parlamento Europeo y del Consejo, sobre el uso de normas para la transmisión de señales de televisión y se aprueban medidas adicionales para la liberación del sector, después sustituido por la Ley 17/1997, de 3 de mayo, del mismo título, que la STJCE de 22 de enero de 2002, había considerado en parte como una violación suficiente caracterizada del Derecho de la Unión Europea15.

Un poco antes de esta sentencia el propio Tribunal Supremo había dado también entrada a la responsabilidad por leyes inconstitucionales a partir de sus sentencias de 29 de febrero, de 13 de junio, de 15 de julio, de 30 de septiembre y dos de 27 de diciembre de $2.000^{16}$ en las que se había indemnizado por los daños causados por la aplicación de una tasa fiscal introducida por la Ley 5/1990, de 29 de junio, sobre Medidas en Materia Presupuestaria, Financiera y Tributaria que después fue anulada por la STC 173/1996, de 31 de octubre. El Tribunal Supremo se alineó en estas sentencias con aquel sector doctrinal que como GARRIDO FALLA defendía que <<toda ley declarada inconstitucional genera un derecho a indemnización a favor de quienes hayan sido perjudicados por la aplicación de la ley $>>^{17}$.

Son estos precedentes jurisprudenciales los que se pretenden ahora reconducir, restringiéndolos, con los preceptos que se contienen en los artículos 32.3, 4 a 6 y 34.1 párrafo segundo del Proyecto de Ley de Régimen jurídico del sector público ${ }^{18}$, como se hizo en su día con el citado artículo 139.3 de la LRJPAC. Por mucho que en la exposición de motivos de este Proyecto de Ley se afirme que entre los cambios legislativos que se introducen merecen una especial mención los <<introducidos en la regulación de la denominada «responsabilidad patrimonial del Estado Legislador» por las lesiones que sufran los particulares en sus bienes y derechos derivadas de leyes declaradas inconstitucionales o contrarias al Derecho de la Unión Europea, concretándose las condiciones que deben darse para que se pueda proceder, en su caso, a la indemnización que corresponda>>.

\section{Aspectos generales aplicables a la responsabilidad por leyes inconstitucionales o contrarias al Derecho de la Unión europea}

Con carácter general el artículo 32.3 del PLRRJJSP establece que a la responsabilidad por leyes inconstitucionales y contrarias al Derecho de la Unión Europea, dejando incomprensiblemente fuera a la que tenga su origen en leyes válidas, les serán aplicables los requisitos establecidos en sus dos primeros apartados en los que se recoge que el daño tiene que ser antijurídico, porque quién sufra el daño no tenga la obligación jurídica de soportarlo <<de acuerdo con la ley >> (Art. 32.1) y que este daño además <<habrá de ser efectivo, evaluable económicamente e individualizado con relación a una persona o grupo de personas $>$ (Art. 32.2). Estos requisitos vendrían a conformar en nuestro ordenamiento jurídico los principios que serían aplicables a la responsabilidad patrimonial de los poderes públicos aunque de forma "miope" en la rúbrica de la Sección donde se encuentra el precepto sólo se haga referencia a la Responsabilidad patrimonial de las Administraciones Públicas ${ }^{19}$.

12 TJCE 1996/37.

13 Junto a las exigencias de que se atribuyan derechos a favor de particulares derivados del Derecho de la Unión Europea, que puedan ser identificables y que exista una relación de causalidad entre el incumplimiento de la obligación que incumbe al Estado y el daño sufrido por las personas afectadas. Véase a in extenso a ALONSO GARCÍA, R. en su La responsabilidad de los Estados miembros por infracción del Derecho comunitario, Madrid, Civitas, 1.997.

14 RJ $2003 / 8844$.

15 F.J. $12^{\circ}$.

16 RJ 2000/2730, 5939, 7423, 9093, 9575 y 9576.

17 En su Sobre la responsabilidad del Estado Legislador, Revista de Administración Pública, n 118, 1989, pág. 53. En este mismo sentido aunque con una fundamentación opuesta se muestran GÓMEZ PUENTE, M. en su La inactividad del legislador: una realidad susceptible de control, Mc GrawHill, Madrid, 1997, pág. 10 y RODRíGUEZ OLIVER, J.M. en Los ámbitos exentos del control del Tribunal Constitucional, publicado en el libro colectivo El tribunal Constitucional, Vol. III, Dirección general de lo contencioso-administrativo del Estado, Instituto de Estudios fiscales, 1981 , Madrid, págs. 2355 y 2356.

18 En la redacción final que se dio al que ahora es el artículo 32.3 del Proyecto de Ley de Régimen jurídico del Sector público, y que inicialmente figuraba en el artículo 75.3 del Proyecto de Ley de Procedimiento administrativo común de las Administraciones Públicas, el Gobierno reprodujo literalmente el texto que el Consejo de Estado le sugirió en su Dictamen $n^{\circ} 275 / 2015$, de 29 de abril, recaído sobre el anteproyecto de este último texto en el Punto 15.a).1. Supuestos de sus Observaciones particulares.

19 Sección $1^{\text {a }}$ del Capítulo IV del Título Preliminar de este Proyecto de Ley. 
Como critica el Consejo de Estado en su Dictamen 275/2015, de 29 de abril ${ }^{20}$, resulta complejo y disfuncional aplicar unos mismos requisitos a dos clases de responsabilidad, la administrativa y la legislativa, que tienen una naturaleza jurídica completamente distinta. De todos estos requisitos, desde el luego, el que mayor complejidad plantea en su aplicación a la responsabilidad legislativa, como ha destacado la doctrina ${ }^{21}$, es el de la antijuridicidad del daño por cuanto el daño en la responsabilidad por ilícito legislativo tiene su origen en la aplicación de una ley, aunque en estos supuestos se trate de leyes inválidas.

La responsabilidad derivada de la aplicación de una ley inconstitucional o contraria al Derecho de la Unión Europea tiene un presupuesto previo inexcusable, la previa constatación jurisdiccional de la invalidez de la ley a la que se le imputa el daño. Esta necesidad de que preceda una declaración de inconstitucionalidad de la ley o de que se dicte un pronunciamiento jurisdiccional en el que se determine que la disposición legal causante del daño es contraria al Derecho de la Unión Europea aparece recogida expresamente tanto en las letras a) y b) del apartado 3 de este precepto como en sus posteriores apartados 4 a 6 . Ahora bien, este último apartado 6 tiene un contenido que no es técnicamente correcto cuando se refiere a las leyes contrarias al Derecho de la Unión Europea. Según este precepto la <<sentencia que declare la inconstitucionalidad de la norma con rango de ley o declare el carácter de norma contraria al Derecho de la Unión Europea producirá efectos desde la fecha de su publicación en el «Boletín Oficial del Estado» o en el «Diario Oficial de la Unión Europea», según el caso, salvo que en ella se establezca otra cosa»>. En el caso de la inconstitucionalidad de las leyes en los procedimientos de inconstitucionalidad, que se pueden iniciar a través de un recurso de inconstitucionalidad, de una cuestión de inconstitucionalidad o que pueden suscitarse en la tramitación de un recurso de amparo o de un conflicto en defensa de la autonomía local22, se concluye con un fallo del Tribunal Constitucional en el que se declara la inconstitucionalidad de las normas legales enjuiciadas. Pero no sucede lo mismo con las leyes que sean contrarias al Derecho de la Unión Europea. No hay en nuestro ordenamiento jurídico ningún procedimiento jurisdiccional que culmine con una resolución, sea del Tribunal de Justicia de la Unión Europea o de nuestros propios órganos jurisdiccionales, que pueda tener como resultado una declaración expresa en este sentido. El Tribunal de Luxemburgo puede declarar el incumplimiento por parte de España de sus obligaciones derivadas del Derecho de la Unión Europea a través de distintos procedimientos ${ }^{23}$, pero no declarar que una ley española es contraria a este Derecho. Igualmente los órganos judiciales españoles únicamente podrán inaplicar una ley que sea contraria al Derecho de la Unión Europea. Por lo que estos preceptos, de resultar finalmente aprobados con este tenor, habrán de someterse a una corrección interpretativa.

Tampoco recogió el Gobierno en este precepto la más que razonable sugerencia que le hizo el Consejo de Estado, en su reiterado Dictamen $n^{\circ}$ 275/2015, de 29 de abril24, de incluir expresamente la posibilidad de que el incumplimiento del Derecho de la Unión Europea pudiera tener su origen en la falta de transposición de una Directiva, como sucedió por ejemplo en la ya citada sentencia Francovich y Bonifaci.

La principal diferencia que existía inicialmente en la jurisprudencia del Tribunal Supremo entre la responsabilidad por leyes inconstitucionales y leyes contrarias al Derecho de la Unión Europea estribaba en que en los supuestos de leyes inconstitucionales no se exigía que quienes hubiesen sufrido el daño hubiesen impugnado previamente la actuación administrativa con la que eventualmente se le hubiese aplicado la ley viciada. Mientras que en las disposiciones legales que vulneraban el Derecho de la Unión Europea esta impugnación se erigía en una condición sine qua non para la procedencia de la responsabilidad. La razón de esta diferenciación radicaba en que respecto a las leyes contrarias al Derecho de la Unión Europea, al igual que sucede con las disposiciones reglamentarias ilegales, los Jueces y Tribunales españoles si están facultados para dejar de aplicar sus preceptos que estén viciados. Lo que no sucedería con los posibles vicios de inconstitucionalidad que afecten a preceptos legales que tendrían forzosamente que ser cuestionados ante el Tribunal Constitucional. Esta diferencia de trato, como se señala en el reiterado Dictamen del Consejo de Estado 275/2015, de 29 de abril ${ }^{25}$, se quebró tras la sentencia de 26 de enero 2010, Caso Transportes Urbanos y Servicios Generales, S.A.L. contra Administración del Estado dictada por la Gran Sala del Tribunal de Justicia de la Unión Europea, resolviendo la cuestión que le había planteado el propio Tribunal Supremo español, donde se sostuvo inequívocamente que <<el Derecho de la Unión se opone a la aplicación de una regla de un Estado miembro en virtud de la cual una reclamación de responsabilidad patrimonial del Estado basada en una infracción de dicho Derecho por una Ley nacional declarada mediante sentencia del Tribunal de Justicia

20 En su punto 15.a) 1. Supuestos de las Observaciones particulares.

21 Como destacara GARRIDO FALLA, F. en La responsabilidad del Estado Legislador en la nueva Ley 30/1.992 y en..., op. cit., pág. 128.

22 Arts. 31, 35, 55.2 y 75. Quinque.6 de la Ley orgánica 2/1979, de 3 de octubre, del Tribunal Constitucional.

23 Por la vía del recurso por incumplimiento o a través del planteamiento de una cuestión prejudicial (Arts. 260 y 267 del Tratado de Funcionamiento de la Unión Europea)

24 Párrafo $9^{\circ}$ del Punto 15.a).2. Requisitos de las Observaciones particulares del Dictamen 275/2015, de 29 de abril.

25 Idem. párrafos $6^{\circ}$ a $8^{\circ}$. 
dictada con arreglo al artículo 226 CE sólo puede estimarse si el demandante ha agotado previamente todas las vías de recurso internas dirigidas a impugnar la validez del acto administrativo lesivo dictado sobre la base de dicha Ley, mientras que tal regla no es de aplicación a una reclamación de responsabilidad patrimonial del Estado fundamentada en la infracción de la Constitución por la misma Ley declarada por el órgano jurisdiccional competente $>\left(\text { Parágrafo } 48^{\circ}\right)^{26}$.

Lo que llevó al Tribunal Supremo a rectificar su doctrina anterior a partir de la STS de 14 julio $2010^{27}$ dejando de exigir la previa impugnación de los actos administrativos de aplicación de la ley contraria al Derecho de la Unión Europea para que pueda proceder una indemnización. En el Proyecto de Ley, con el beneplácito del Consejo de Estado $^{28}$, el Gobierno pretende ahora rectificar esta jurisprudencia para pasar a exigir en todos los supuestos de responsabilidad por ilícito legislativo, tanto los basados en la inconstitucionalidad de una ley como los que tengan su origen en una violación del Derecho de la Unión Europea, el previo agotamiento de los recursos administrativos y judiciales que puedan proceder contra la aplicación administrativa de la ley viciada. De este modo en los apartados 4 y 5 del artículo 32 del PLRJSP se establece como requisito para la procedencia de la responsabilidad en ambos supuestos que el particular lesionado <<haya obtenido, en cualquier instancia, sentencia firme desestimatoria de un recurso contra la actuación administrativa que ocasionó el daño >. Exigiéndose, además como nuevo obstáculo procesal, que en esta impugnación se hubiese alegado la inconstitucionalidad o la infracción del Derecho de la Unión Europea, después declarada.

Es discutible que con esta regulación se cumpla con el principio de efectividad que exige la jurisprudencia del Tribunal de Justicia de la Unión Europea que prohíbe que una regulación nacional pueda establecer unas condiciones que de facto imposibiliten el reconocimiento de responsabilidad derivada de una infracción imputable a un Estado miembro del Derecho de la Unión Europea porque <<hagan prácticamente imposible o excesivamente difícil obtener reparación >>29. Lo que es indudable es que con esta regulación se va a alentar innecesariamente una elevadísima litigiosidad con un mero carácter preventivo, que resulta difícilmente justificable.

\section{La errónea exigencia de que los daños tengan su origen en la aplicación administrativa de las leyes inconstitu- cionales o contrarias al Derecho de la Unión Europea}

En el Proyecto de Ley comentado el Gobierno, siguiendo en esta ocasión la recomendación que le formuló el Consejo de Estado ${ }^{30}$ y también el precedente del artículo 139.3 de la LRJPAC, parece reducir la responsabilidad por ilícito legislativo a los supuestos en los que los daños que sufran los particulares sean consecuencia de una actuación administrativa de aplicación de la ley inconstitucional o contraria al Derecho de la Unión Europea. Con esta solución se deja sin regulación aquellos casos en los que los daños sean imputables a leyes autoaplicactivas, que no requieran de una ulterior actividad administrativa de aplicación, y también los supuestos en los que los daños causados por leyes inválidas se produzcan en relaciones jurídicas entre particulares.

Y no es porque no se hubieran dado ya en nuestro país supuestos de esta naturaleza. Destaca, por ejemplo, el asunto que resolvió la importante sentencia de la Sala de lo contencioso-administrativo del Tribunal Supremo de 2 junio de $2010^{31}$ en la que, anulando el acto presunto de denegación de la reclamación de responsabilidad patrimonial por los perjuicios causados como consecuencia de la aplicación del Real Decreto-Ley 5/2002, de mayo, de Medidas urgentes para la reforma del sistema de protección de desempleo y la mejora de la ocupabilidad que fue declarado inconstitucional por la STC 68/2007, de 28 de marzo ${ }^{32}$, se indemnizó a un trabajador despedido de una empresa que no pudo cobrar los salarios de tramitación que esta Disposición legal había suprimido. Igualmente la sentencia de la Audiencia Nacional, de 7 mayo $2002^{33}$, condenó al Estado a indemnizar a un particular que no había podido ejercitar su derecho a resolver un contrato privado de mulitpropiedad, que reconocía la Directiva 94/47/ CE, de 26 de octubre, del Parlamento y del Consejo relativa a la multipropiedad, porque esta disposición había sido transpuesta con retraso por España.

\footnotetext{
26 TJCE 2010/26.

27 RJ 2010/6245.

28 Inciso final del párrafo $8^{\circ}$ del Punto 15.a).2. Requisitos de las Observaciones particulares del Dictamen 275/2015, de 29 de abril.

29 Sobre el alcance del principio de efectividad puede consultarse, por todas, la STJCE, de la Gran Sala, de 24 de marzo de 2009 , caso Danske Slagterier contra Bundesrepublik Deutschland (TJCE 2009/63).

30 En el párrafo $2^{\circ}$ del reiterado Punto 15.a).2. Requisitos las Observaciones particulares del Dictamen 275/2015, de 29 de abril.

31 JUR 2010, 288332. Esta sentencia fue dictada por el Pleno del Tribunal Supremo y cuenta con seis jugosos votos particulares.

32 Porque el alto Tribunal no apreció que concurriese el presupuesto habilitante de la urgente y extraordinaria necesidad (F.J. $\left.12^{\circ}\right)$.

33 SAN de 7 mayo 2002 (RJCA 2002/634).
} 


\section{Limitación temporal del alcance de la responsabilidad por ilícito legislativo}

Por si fueran pocas las restricciones que el Proyecto de Ley de Régimen jurídico del Sector público establece para que se pueda reconocer en nuestro ordenamiento jurídico responsabilidad por ilícitos legislativos se introducen en sus artículos 32.6 y 34.1, párrafo segundo, una serie de importantes limitaciones temporales.

En el primero de estos preceptos, que más arriba ya se ha transcrito, se pretende limitar pro futuro los efectos de las sentencias que declaren la inconstitucionalidad de la ley, o de algunos de sus preceptos, y aquellas en las que se haga constar un incumplimiento del Derecho de la Unión Europea imputable a un precepto legal español. Estableciendo que, salvo que en el fallo jurisdiccional <<se establezca otra cosa〉>, los efectos de estas sentencias se producirán <<desde la fecha de su publicación en el «Boletín Oficial del Estado» o en el «Diario Oficial de la Unión Europea >. Sin entrar a valorar aquí la más que discutible viabilidad jurídica de que en una disposición que tiene rango de ley ordinaria, como sería la futura Ley de Régimen jurídico del Sector público, se pueda tratar de determinar los efectos de las sentencias de los Jueces y Tribunales españoles y nada menos que de las del Tribunal Constitucional y del Tribunal de Justicia de la Unión Europea, lo cierto es que se trate de una precepto ininteligible.

Hay que descartar que con este precepto se pretenda limitar la indemnización a los daños que se produzcan con la aplicación de la ley viciada a partir de la publicación oficial de su invalidez. No sólo porque en estos casos la norma habría ya desaparecido del ordenamiento jurídico, en el caso de las leyes inconstitucionales, o se habría constatado ya que es contraria al Derecho de la Unión Europea por lo que si se consintiera su aplicación judicialmente se trataría de un error judicial; sino porque esta interpretación chocaría con lo que dispone el propio Proyecto de Ley precisamente en su artículo 34.1, párrafo segundo, en el que expresamente se establece que serán indemnizables <<los daños producidos en el plazo de los cinco años anteriores a la fecha de la publicación de la sentencia que declare la inconstitucionalidad de la norma con rango de ley o el carácter de norma contraria al Derecho de la Unión Europea, salvo que la sentencia disponga otra $\cos a>>$. Coletilla final con la que se pretende salvar la facultad del Tribunal $a$ quo de establecer el alcance de sus fallos, de acuerdo con la normativa que le sea aplicable.

Entonces, ¿qué finalidad puede tener el precepto contenido en el artículo 32.6 del Proyecto de Ley? En mi opinión con esta norma se está pretendiendo cerrar el posible franco que se puede abrir tras la publicación de la sentencia en la que se determine la invalidez de la ley con la revisión de oficio de los actos administrativos de aplicación de la ley viciada. Promoviendo la revisión de oficio de estos actos se podría pretender reiniciar la impugnación de esta actuación administrativa cuando no se hubiese hecho con anterioridad. Si esta era la verdadera intención del Gobierno se debería haber explicitado y probablemente haber introducido en el Proyecto de Ley de Procedimiento administrativo común de las Administraciones Públicas ${ }^{34}$ como límite a la potestad de revisión de oficio de los actos administrativo. Otra cosa es que sea constitucional por cuanto limita los efectos de estas sentencias con un alcance difícilmente compatible con el derecho a la tutela judicial efectivo que consagra el artículo 24.1 de nuestra Constitución.

También es cuestionable la constitucionalidad de la limitación temporal de los daños que pueden ser indemnizados en los ilícitos legislativos a los cinco años anteriores a la publicación de la sentencia que determina la invalidez de la ley. No se puede olvidar que los particulares en el ordenamiento jurídico español carecen de acciones directas que le permitan obtener la declaración de inconstitucionalidad de una ley. Y los plazos de los procedimientos de declaración de inconstitucionalidad, aunque sea cierto que se han venido acortando en los últimos tiempos, suelen ser de varios años. Demora en la resolución jurisdiccional que también se da en los procesos judiciales en los que se plantea la conformidad con el Derecho de la Unión Europea de disposiciones legales españolas. No tiene ningún sentido que siendo nula la ley que ha causado el daño la posibilidad de recibir una indemnización se haga depender de la circunstancia aleatoria, para quien lo ha sufrido, de que la sentencia que determine la invalidez se publique dentro del plazo de los cinco años siguientes a su producción. Sin olvidar tampoco lo discutible jurídicamente que es que por medio de una ley ordinaria se pretenda determinar el alcance de fallos jurisdiccionales.

Sorprendentemente la única objeción que el Consejo de Estado hizo a este precepto en su Dictamen 275/2015, de 29 de abril es que el plazo que se había elegido de cinco años no es habitual en el Derecho administrativo. Así, sostiene que resulta <<evidente la necesidad de acotar temporalmente los márgenes en que han de reconocerse las indemnizaciones a que se refiere este nuevo apartado, pero llama la atención que el plazo establecido sea de cinco años, por ser éste un plazo atípico en el ámbito del Derecho administrativo, en el que los derechos y obligaciones de Derecho público prescriben a los cuatro años, siendo el plazo de prescripción de la acción para reclamar indemnizaciones en concepto de responsabilidad patrimonial de un año>>35.

34 La regulación de la revisión de oficio se encuentra en los artículos 106 a 111 de este Proyecto que se puede consultar en http://www. congreso.es/public_oficiales/L10/CONG/BOCG/A/BOCG-10-A-155-1.PDF.

35 Párrafo $2^{\circ}$ del Punto 16) Artículo 77. Indemnización de las Observaciones particulares del Dictamen. 
Han sido muy pocos los supuestos en los que se ha reconocido responsabilidad por ilícito legislativo en nuestro país sin que, que se sepa, haya supuesto una quiebra de la Hacienda pública, ya de por sí muy diezmada. Aplicando esta limitación temporal de cinco años, salvo error u omisión por mi parte, todos ellos habrían sido desestimados, lo que da cuenta de la trascendencia real que este precepto puede llegar a tener en caso de que entré en vigor.

\section{La violación del principio de equivalencia al establecerse en el Proyecto de Ley un régimen más restrictivo para la responsabilidad legislativa derivada del incumplimiento del Derecho de la Unión Europea que el de la respon- sabilidad por daños causados por leyes inconstitucionales}

Queda una última cuestión de calado por abordar de la nueva regulación que con el Proyecto de Ley de Régimen jurídico del Sector público se le pretende dar a la responsabilidad por ilícito legislativo. Analizar si la diferente regulación, más restrictiva, que se establece para los supuestos de responsabilidad derivada del incumplimiento por una ley del Derecho de la Unión Europea en relación a la aplicable a la responsabilidad por leyes inconstitucionales, respeta el principio de equivalencia consagrado por la jurisprudencia del Tribunal Superior de Justicia de la Unión Europea. Este principio impide que los Estados miembros puedan establecer un régimen más favorable a las reclamaciones que se basen en normas de Derecho interno que aquellas que se funden en el Derecho de la Unión Europea.

En el apartado 6 del artículo 32 del Proyecto de Ley se adicionan a los requisitos formales ya examinados, que exigen que haya recaído una declaración de invalidez de la ley y que se hubiese obtenido previamente una sentencia desestimatoria firme en la impugnación de la actuación administrativa de aplicación de la ley que causó el daño donde se hubiese alegado su invalidez, otros dos requisitos materiales como son que la norma de la Unión Europea infringida tenga por objeto conferir derechos a los particulares y que el incumplimiento estatal sea suficientemente caracterizado. Se trata de dos requisitos que la propia jurisprudencia del Tribunal Supremo, en unos términos discutibles, aplica ya a la indemnización por los daños imputables a una ley contraria al Derecho de la Unión Europea. Por lo que en realidad el Proyecto de Ley se ha limitado en este caso a positivar una restrictiva doctrina del Tribunal Supremo, criticada por la doctrina ${ }^{36}$.

Con arreglo a la regulación contenida en el Proyecto de Ley bastará con que una sentencia constitucional declare la inconstitucionalidad de una ley, con independencia de la vulneración en que se haya incurrido, para que, si se reúnen el resto de los requisitos establecidos en los apartados 3, 4 y 5 de su artículo 32, proceda el reconocimiento de una indemnización. Por el contrario, si se trata de una disposición que vulnera el Derecho de la Unión Europea no será suficiente con el cumplimiento de todos estos requisitos. Ya que será necesario además que la norma del Derecho de la Unión Europea hubiese reconocido un derecho subjetivo al particular y que la violación que se haya producido sea suficientemente caracterizada. Lo que a mi juicio vulnera el principio de equivalencia.

Ante esta tesitura cabrían dos soluciones antagónicas. Por supuesto, sería posible eliminar el requisito mínimo establecido por la jurisprudencia del Tribunal de Justicia de la Unión Europea equiparando en nuestro ordenamiento a ambas clases de ilícito legislativo, con lo que bastará que se produzca un pronunciamiento jurisdiccional en el que se determine la invalidez de la disposición legal que causa el daño para que se pueda reconocer una indemnización. Pero existe otra alternativa, aunque sea más compleja jurídicamente, también respetuosa con el principio de equivalencia. El riesgo que existe con la responsabilidad derivada de las leyes inconstitucionales, y que en realidad está detrás de la propuesta de regulación del ilícito legislativo que estamos analizando, es que su carácter generalizado puede dar lugar a una grave carga económica para el Estado. Para conjurar esta consecuencia, como defendí hace ya algún tiempo ${ }^{37}$, se debería conectar la antijuridicidad de los daños provocados por leyes constitucionales, como hace el Tribunal de Justicia de la Unión Europea con las infracciones del Derecho de la Unión Europea, con un requisito material que en nuestro ordenamiento constitucional vendría conformado por la garantía del contenido esencial de los derechos del Capítulo II del Título I protegido por nuestra Constitución ex artículo 53.1 de nuestra Constitución. Con lo que se equipararían los dos supuestos de responsabilidad por ilícito legislativo con la exigencia de unos requisitos materiales muy semejantes con los que además se alejaría el peligro del que advirtiera el maestro GARCÍA DE ENTERRÍA de fiat iustitia, pereat mundis con la aplicación la responsabilidad patrimonial por leyes inconstitucionales ${ }^{38}$.

36 Como hace ALONSO GARCÍA, M. C. en La reciente jurisprudencia sobre la responsabilidad del Estado Legislador frente a daños derivados de leyes inconstitucionales, Revista de Administración Pública, $n^{\circ}$ 157, 2002, págs. 222 y en La responsabilidad patrimonial del Estado Legislador en QUINTANA LÓPEZ, T. (Dir.) y CASARES MARCOS, A. (Coord), Responsabilidad patrimonial de la Administración Pública. Estudio general y ámbitos sectoriales, tirant lo blanch, Valencia, 2009, págs. 502 a 504 y yo mismo en La evolución expansiva de la responsabilidad de los poderes públicos, LÓPEZ MENUDO, F. (Coord.), Derechos y garantías del ciudadano: estudios en homenaje al profesor Alfonso Pérez Moreno, lustel, 2011, pág. 619 .

37 Vid. De la Teoría a la realidad de la responsabilidad del Estado Legislador, op. cit., pág. 317.

38 En su La responsabilidad patrimonial del Estado Legislador en el Derecho español, op. cit., pág. 273. 
Con todo habría sido deseable que el Gobierno hubiese seguido la recomendación que le hizo el Consejo de Estado en su reiterado Dictamen 275/2015, de 29 de abril, y hubiese introducido en un texto normativo independiente la regulación de la responsabilidad de los poderes públicos ${ }^{39}$ en desarrollo de lo previsto en los artículos 9.3, 121 y 106.2 de la Carta magna al amparo de los títulos competenciales contenidos en las cláusulas $5^{\mathrm{a}}$ y $18^{\mathrm{a}}$ de su artículo 149. Lo que contribuiría notablemente a generar seguridad jurídica en una materia de tanta trascendencia como esta en un momento en el que desgraciadamente brilla por su ausencia en nuestro país. 